\title{
TROMBOSE VENOSA PÓS-OPERATÓRIA
}

\author{
POSTOPERATIVE VENOUS THROMBOSIS
}

Carlos Eli Piccinato

Docente da Divisão de Cirurgia Vascular e Endovascular do Departamento de Cirurgia e Anatomia da FMRP-USP

Correspondência: Divisão de Cirurgia Vascular e Endovascular do Departamento de Cirurgia e Anatomia da FMRP-USP. email: cepiccin@fmrp.usp.br

Piccinato CE. Trombose venosa pós-operatória. Medicina (Ribeirão Preto) 2008; 41 (4): 477-86.

RESUMO: A trombose venosa profunda ou superficial é a formação de trombos no sistema venoso e faz parte dos fenômenos trombo-embólicos. Neste texto são discutidos a etiopatogenia, o diagnóstico clínico e laboratorial, a profilaxia da trombose venosa no paciente cirúrgico.

Descritores: Trombose Venosa. Período Pós-Operatório.

\section{1- INTRODUÇÃO}

Trombose venosa é a formação aguda de trombos (coágulos) no sistema venoso superficial ou profundo, provocando oclusão total ou parcial da veia. Os trombos formam-se espontaneamente ou como resultado de lesão parietal traumática ou inflamatória. Emprega-se a denominação de trombose venosa profunda (TVP) quando os trombos atingem o sistema venoso profundo e tromboflebite superficial quando as veias superficiais são acometidas (Figura 1).

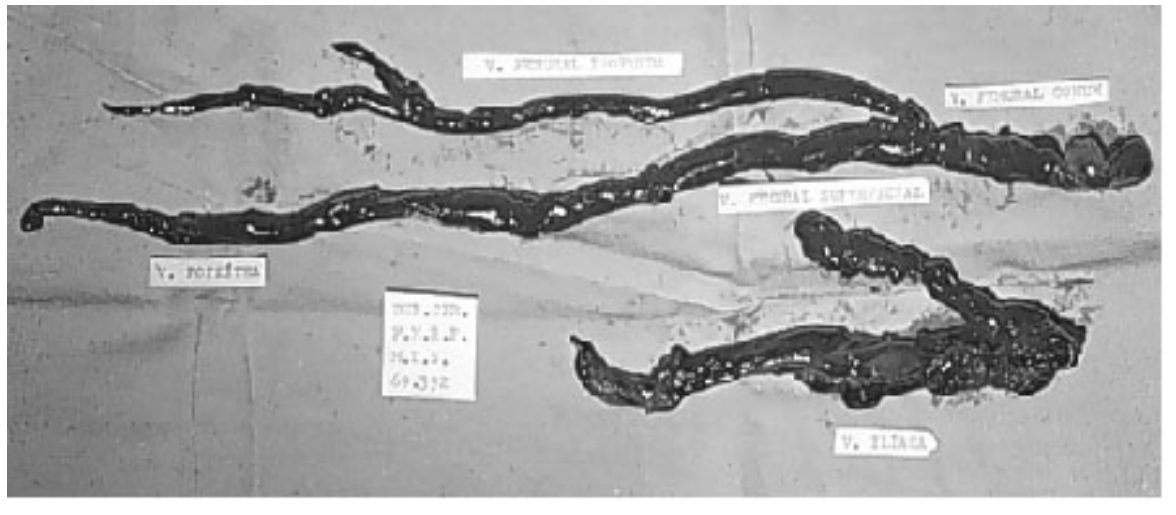

Figura 1: Trombos retirados do sistema venoso profundo de membros inferiores.
Os trombos formados em veias profundas e mais raramente no sistema venoso superficial podem se fragmentar e migrar na corrente circulatória (via coração direto) e se alojar na artéria pulmonar e ramos constituindo uma complicação grave freqüentemente fatal que é a embolia pulmonar.

Em estudo retrospectivo realizado no Hospital das Clínicas da FMRP-USP de 3012 necrópsias seriadas, foram encontrados 177 (5,8\%) casos de embolia pulmonar ${ }^{1}$. Entretanto, estudos prospectivos revelam incidência bem maior (10 a 20\%)2. Na grande maioria dessas mortes por embolia pulmonar o diagnóstico prémorte não atinge $1 / 3$ delas ( 5 a $30 \%)^{2}$.

A TVP é muito comum em pacientes hospitalizados, politraumatizados, no pós-operatório de cirurgias de grande porte, em idosos, em gestantes pósparto, portadores de doenças neoplásicas malignas, inflamatórias, infecciosas e degenerativas e pode levar à morte súbita por embolia pulmonar. 
Além da embolia pulmonar há outras complicações da TVP, não menos graves. Após a fase aguda da trombose sobrevem a fibrinólise que é capaz de lisar o trombo. Esta lise pode ser efetiva ou não. Assim, a veia pode ser desobstruída e recuperar sua função ou o trombo pode se aderir à parede venosa e resultar em obstrução parcial ou total da veia (organização do trombo).

Quando há organização do trombo (aderência) a veia terá dificuldade em manter a drenagem sangüínea, particularmente no sistema venoso profundo dos membros inferiores. Essa disfunção venosa resulta em estase venosa. Esta complicação tardia da trombose venosa é conhecida por síndrome póstrombótica. Estima-se que a prevalência desta síndrome na população seja de $1-3 \% .^{3}$

Quando na fase aguda da trombose venosa profunda os trombos atingem e ocluem praticamente todo o sistema venoso profundo há dificuldade de perfusão dos tecidos pelo sistema arterial, resultando em quadros gravíssimos de gangrena venosa (trombose maciça), felizmente raros.

Resumidamente, na fase aguda da TVP há risco iminente de embolia pulmonar e raramente gangrena venosa, mas tardia e cronicamente este problema poderá cursar com síndrome pós-trombótica (edema, varizes secundárias, dermite ocre, etc.) nos membros inferiores.

A TVP pós-operatória é uma complicação temida pelo cirurgião e todos os esforços são feitos com o objetivo de evitar profilaticamente este problema. A profilaxia da TVP em pacientes operados será discutida neste capítulo.

\section{2- ETIOPATOGENIA E FISIOPA- TOLOGIA}

Virchow, em 1956, descreveu pela primeira vez os fatores primários (válidos até hoje) que predispõem os pacientes à TVP, a chamada tríade de Virchow: coagulabilidade aumentada, lesão endotelial e estase venosa.

O mecanismo de formação de coágulos (coagulação) pode ser resumido na cascata da coagulação sangüínea pela ação da via intrínseca e/ou extrínseca resultando na formação da trombina que age sobre o fribrinogênio circulante formando a rede de fibrina (Figura 2).
O organismo dispõe também de mecanismos protetores que evitam a trombose por meio de inativação dos fatores ativados da coagulação (proteínas C e $\mathrm{S}$ e antitrombina III), eliminação dos fatores ativados da coagulação e a fibrinólise (que promove a lise dos coágulos).

O desbalanço entre os fatores trombogênicos e os protetores, com o predomínio dos primeiros, desencadeia a trombose venosa.

A estase venosa e a lesão endotelial são consideradas fatores desencadeantes, enquanto que a hipercoabulabilidade (coagulabilidade aumentada) pode ser considerada como fator predisponente.

Durante as operações de grande porte, reconhece-se aumento dos fatores de coagulação, diminuição da atividade fibrinolítica e estase venosa por imobilidade no leito; entretanto, a lesão endotelial nem sempre é caracterizada. Assim, quando um paciente é submetido à cirurgia torácica e abdominal e a TVP se manifesta em veias da panturrilha (que é o local mais comum), fica difícil comprovar a lesão endotelial dessas veias. Alguns acreditam que o apoio da panturrilha no plano rígido da mesa cirúrgica poderia desencadear a lesão endotelial.

A tromboflebite superficial por cateterismo venoso é uma complicação freqüente em pacientes cirúrgicos ou clínicos, nos quais fica evidente o risco de lesão endotelial (trauma pelo cateter, a natureza e a osmolaridade da substância administrada são potenciais causadores da lesão). Este tema será abordado mais detalhadamente no final deste capítulo.

\section{CASCATA DE COAGULAÇÃO SANGUÍNEA}

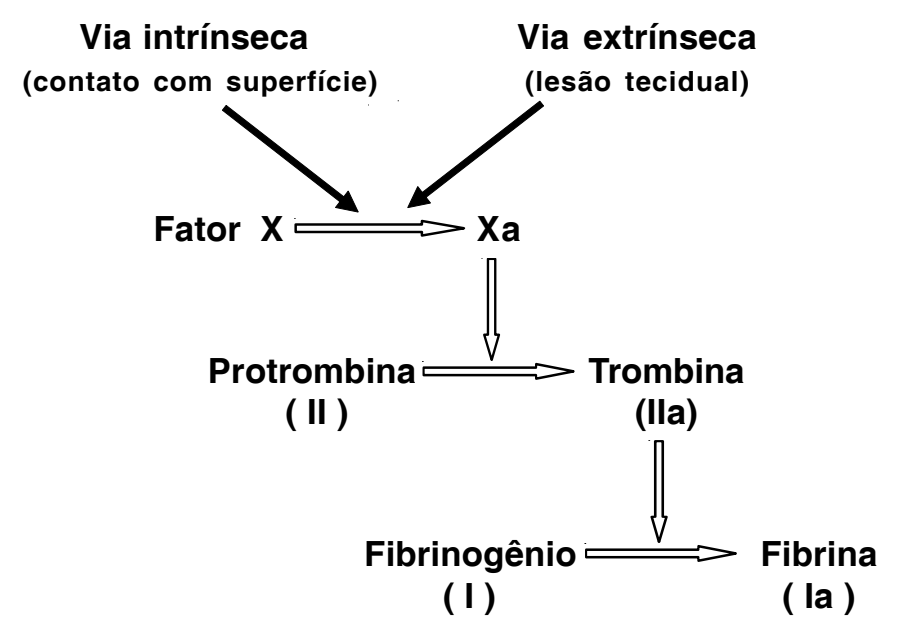

Figura 2: Cascata de coagulação sangüínea. 
Reconhecem-se algumas condições como fatores da trombogênese venosa que, quando associada ao trauma cirúrgico, pode multiplicar o risco de desencadear a TVP:

- Insuficiência cardíaca: o risco de TVP aumenta de 2 a 3 vezes, justificado pelo aumento da pressão venosa central, diminuição da velocidade de fluxo sangüíneo e a imobilidade do paciente.

- Gravidez e puerpério: após o parto a incidência de TVP é maior provavelmente pela liberação de tromboplastina tecidual, diminuição da atividade fibrinolítica e a estase venosa.

- Anticoncepcional oral (ACO): O risco de TVP é maior quanto maior for a dosagem de estrógenos. As pílulas anticoncepcionais atuais apresentam níveis mais baixos de estrógenos do que as antigas. O estrógeno tende a aumentar os níveis de fatores de coagulação, reduz os níveis de antitrombina III (protetor) e diminui o ativador do plasminogênio.

- Idade: Raramente a TVP surge em pacientes jovens. É mais comum após os 40 anos e principalmente após os 60 anos.

- Imobilização: pacientes imobilizados (pós-acidente vascular cerebral, pacientes acamados, etc.), após 1 semana a chance de desenvolver TVP é de 15 a $30 \%$, mais de uma semana o risco é de $80 \%$.Em pacientes com acidente vascular cerebral a TVP é mais comum no membro paralisado(63\%)que no membro oposto(7\%).

- Tromboembolismo venoso prévio: A ocorrência prévia de TVP aumenta 3 a 4 vezes o risco de TVP em pacientes submetidos à cirurgia justificada pela predisposição do indivíduo a fatores locais ou fatores trombofílicos ou presença de neoplasia maligna.

- Obesidade: O risco de TVP aumenta em virtude da dificuldade de mobilização e diminuição da atividade fibrinolítica.

- Varizes: O risco de TVP aumenta 2 vezes em portadores de varizes de membros inferiores.

- Infecção: Infecções graves são consideradas fatores importantes para desenvolver TVP.

- Neoplasias malignas: neoplasias malignas de pulmão, próstata, tubo digestivo e de origem hematogênicas (linfomas, leucemias, etc.) aumentam o risco de 2 a 3 vezes de desenvolver TVP, provavelmente devido ao fato destes tumores formarem fatores pró-coagulantes e pela diminuição da atividade fibrinolítica.

- Trombofilia: algumas condições hereditárias ou adquiridas aumentam o risco de desenvolver trombose venosa. Assim, pacientes com deficiência hereditária de antitrombina III, proteínas $\mathrm{C}$ e $\mathrm{S}$ apresentam potencial de desenvolver TVP. Mas outros fatores apresentam maior risco; resistência à proteína C ativada (fator de Leyden), mutação da protrombina (fator II) e níveis elevados de fator VIII são mais trombogênicos.

Algumas condições clínicas adquiridas que se manifestam com deficiência de plasminogênio, disfibrinogenemia, presença de antifosfolipídicos (fator lúpico) e hiper-homocisteinemia também são trombogênicas. Todos estes fatores, quando associados a outros tipos de cirurgias de grande porte (abdominal ou torácica) multiplicam os riscos.

- Cirurgia: As cirurgias de grande porte, cuja duração ultrapassa 30 minutos apresentam alto risco de desenvolver TVP pós-operatória.

Pesquisas desenvolvidas em pacientes submetidos a operações abdominais e torácicas utilizando-se o teste do fibrinogênio marcado com $\mathrm{I}^{125}$ demonstraram que a TVP se instala principalmente em membros inferiores, cuja incidência varia de 10-42\% nas abdominais e 26 a $65 \%$ nas cirurgias torácicas (Tabela I).

Tabela I: Incidência de TVP* em pacientes cirúrgicos**

\begin{tabular}{lc}
\hline Tipo de cirurgia & Incidência (\%) \\
\hline Abdominal & $10-42$ \\
Torácica & $26-65$ \\
Histerectomia abdominal & 23 \\
Prostatectomia transvesical & $24-47$ \\
Prostatectomia transuretral & $6-8$ \\
Quadril & $41-75$ \\
\hline
\end{tabular}

* TVP = trombose venosa profunda ** Com base no teste do fibrinogênio marcado

Utilizando-se o mesmo método diagnóstico de TVP (teste do fibrinogênio marcado) conseguiu-se comprovar que é durante a operação, aproximadamente em metade delas (50\%) se formam os trombos. Nas primeiras 48 horas formam-se $30 \%$ deles e até o $7^{\circ}$ dia de pós-operatório aproximadamente $20 \%{ }^{4}$. Felizmente, $80 \%$ deles são lisados (mecanismo de fibrinólise) e somente $20 \%$ propagam-se para veias maiores. ${ }^{4}$ 
O local de formação desses trombos preferentemente é nas veias das panturrilhas $(90 \%)$ e em menor número nas grandes veias ilíacas e femorais (5\%) e no coração direito $(5 \%)^{4}$ (Figura 3 ).

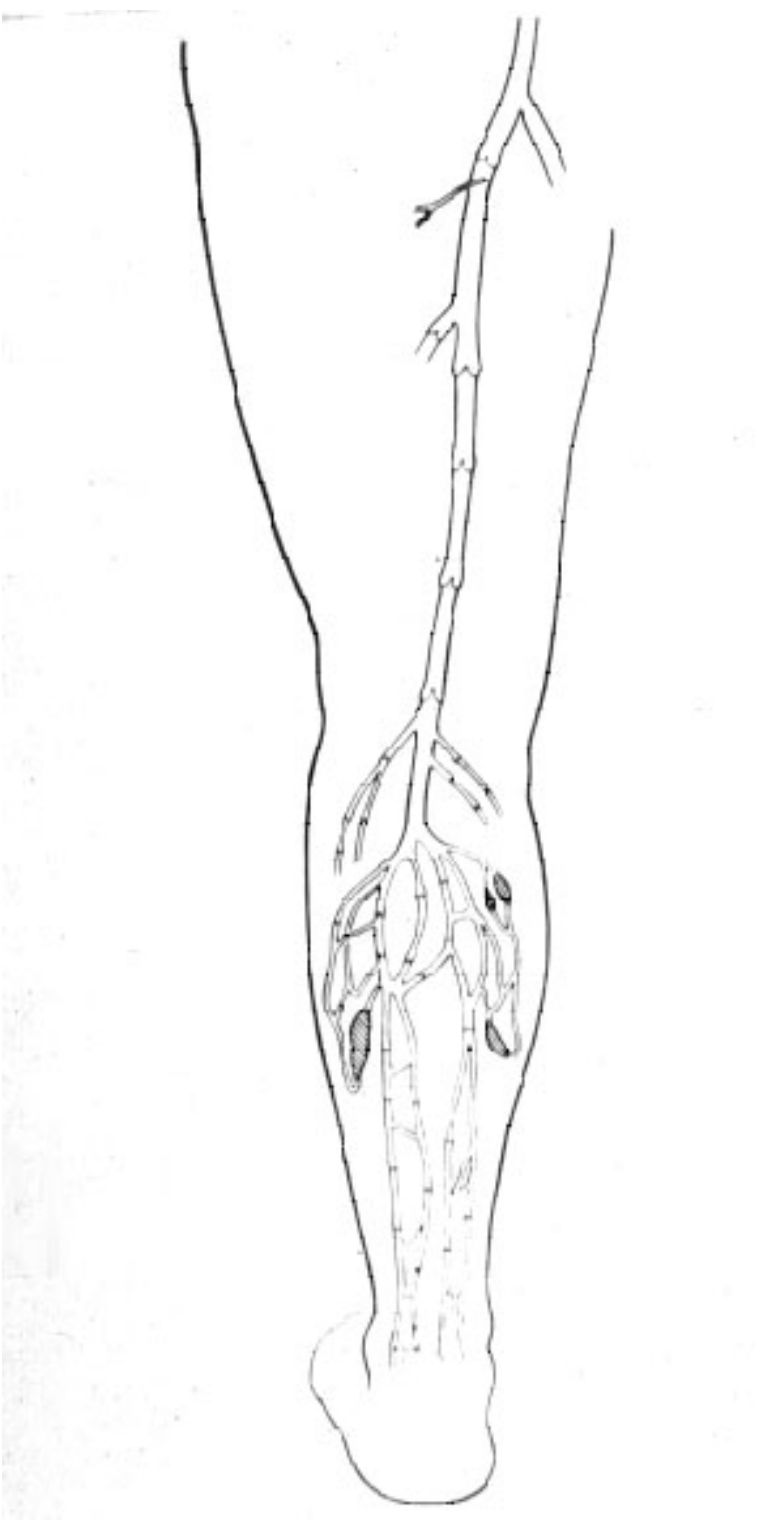

Figura 3: Local preferencial de formação dos trombos pós-operatórios (seios venosos soleares).

Distinguem-se nos trombos a cauda, trombo primário, trombo vermelho, cabeça e trombo branco (plaquetário). A fragmentação da cabeça do trombo propicia a migração na corrente circulatória até o coração direito e a seguir para a artéria pulmonar (Figura 4).

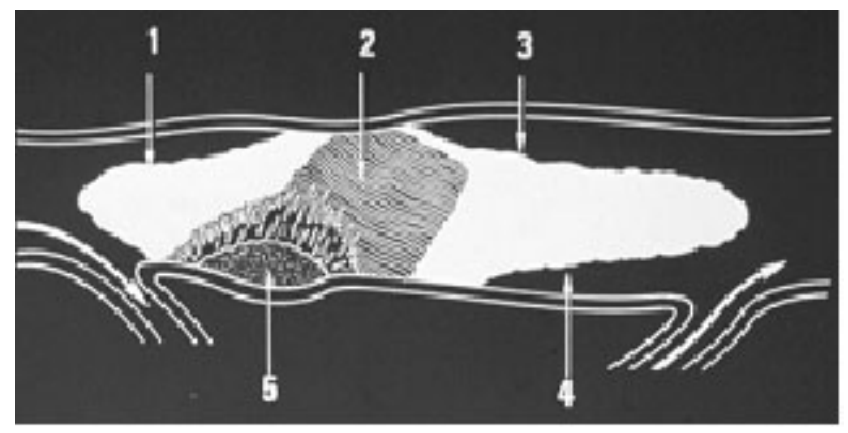

Figura 4: Morfologia do trombo. 1) Cauda; 2) Trombo Primário; 3) Trombo vermelho; 4) Cabeça; 5) Trombo branco (plaquetário).

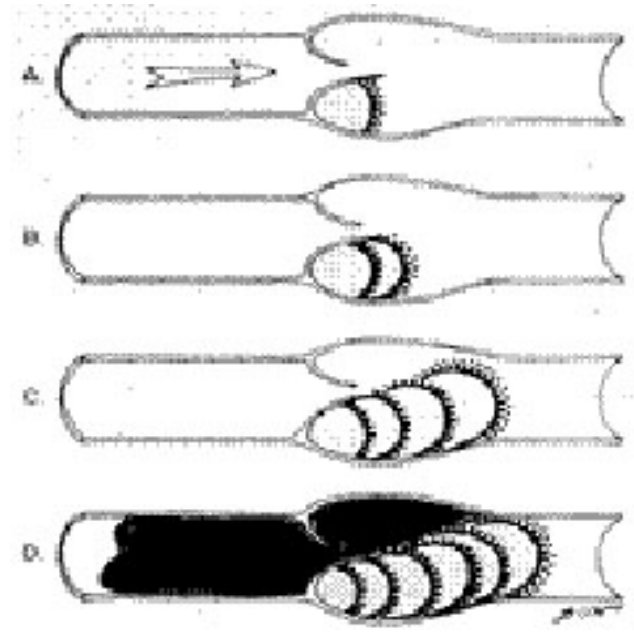

Figura 5: Formação do trombo.

Sevitt sugere que a formação dos coágulos inicia-se junto às cúspides das válvulas venosas (Figura 5).

- Anestesia: O tipo de anestesia utilizado durante operação parece influenciar no risco de desenvolver a TVP.O risco parece ser maior na anestesia geral que na peridural.

- Quimioterapia: Além da neoplasia em si,o próprio tratamento,especialmente o quimioterápico, pode estar implicado no aumento do risco trombótico.

- Grupos sanguiíneos: aparentemente os pacientes do grupo A são mais susceptíveis que os do grupo $\mathrm{O}$.

\section{3- DIAGNÓSTICO CLÍNICO DA TROMBO- SE VENOSA PROFUNDA}

1) Clinicamente a TVP produz poucos sintomas específicos e assim sua caracterização pode ser difícil. Basicamente a obstrução parcial ou total de 
veias profundas pode dificultar a drenagem do membro. Com o aumento da pressão venosa haverá distalmente edema e dor nos quadros mais típicos. O edema dos músculos caracterizam-se por "empastamento" (diminuição do balonamento dos músculos da panturrilha) e a dor à palpação ou na dorso-flexão do pé caracterizam o chamado "sinal de Homans" (Figura 6).

Outras características clínicas e o tratamento da TVP de extremidades serão abordados no $4^{\circ}$ ano, na Disciplina do Sistema Cardiovascular (RCG433).

Além dos sinais e sintomas que podem sugerir a TVP, métodos de imagens são utilizados para pesquisá-la em todos os casos suspeitos .
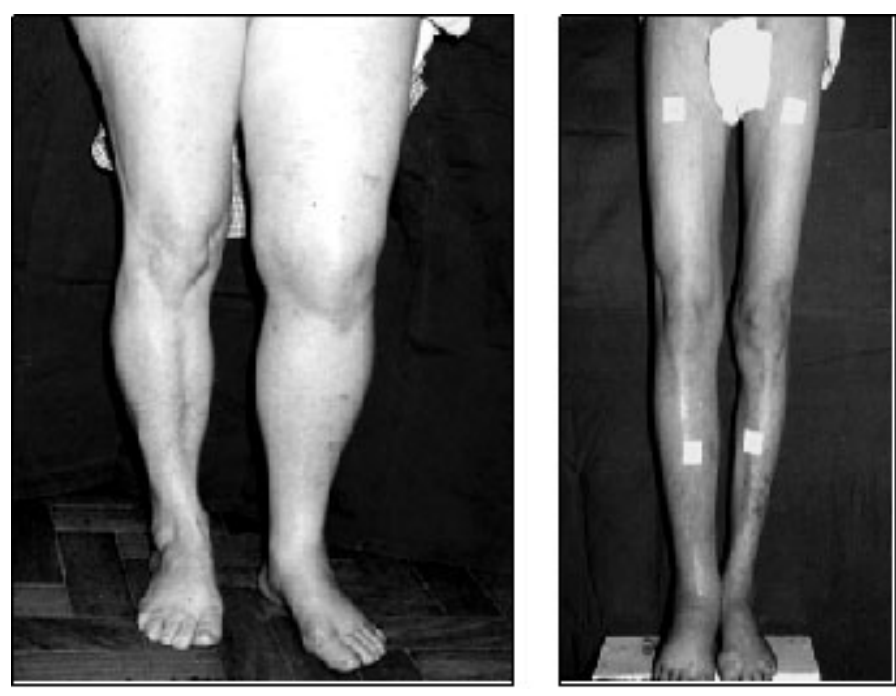

Figura 6: Edema da panturrilha $E$ em relação à $D(A)$ e edema da coxa, perna e pé $D(B)$

2) Métodos de imagens mais comuns:

\section{- Ultrassonografia (Mapeamen-} to Duplex): É o mais utilizado por não ser invasivo; associa a ecografia (imagem modo B) e o estudo do fluxo venoso com o Doppler. A imagem da veia com trombo aparece hiperecogênica e as paredes venosas não colapsam com as manobras compressivas com o transdutor (Figura 7).

- Flebografia: É considerada o
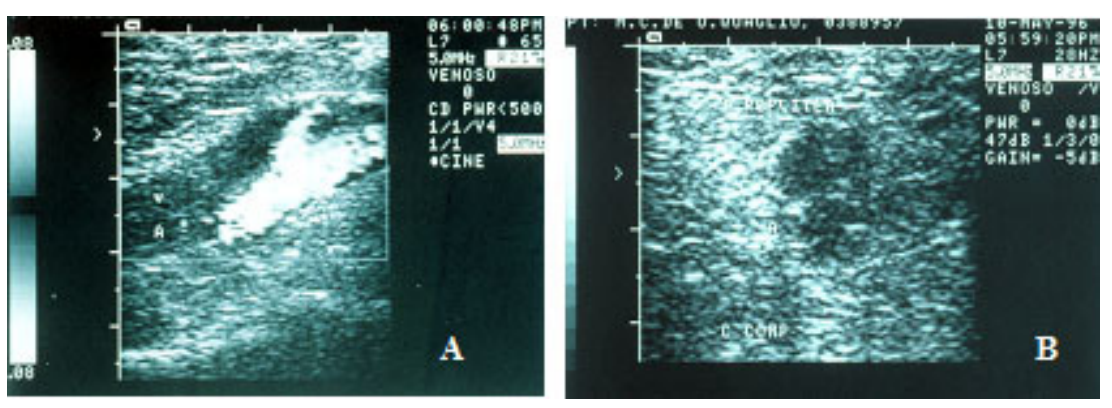

Figura 7: Mapeamento Duplex.

A) imagem longitudinal ( $v=$ veia poplítea);

B) imagem transversa da veia poplítea com trombo (não colapsa). padrão ouro no diagnóstico da TVP. Tem alta sensibilidade e especificidade. Entretanto, o método utiliza contrastes iodados (riscos de alergia, etc) e a injeção destes contrastes deve ser feita em veia distal da extremidade e forçados a transitar no sistema venoso profundo (Figura 8). A flebografia é empregada somente quando a ecografia (US) for inconclusiva e houver forte suspeita de TVP.

- Teste do Fibrinogênio Marcado $\left(\mathrm{I}^{125}\right)$. Este método é utilizado somente em pesquisa clínica, pois só é válido quando o paciente recebe, previamente, o fibrinogênio marcado e no caso de se desenvolver TVP, o fibrinogênio se transforma em fibrina, que se deposita, e esta inicia o processo trombótico. Este método foi utilizado em pesquisas para se investigar os riscos de TVP em situações clínicas e cirúrgicas. Entre-
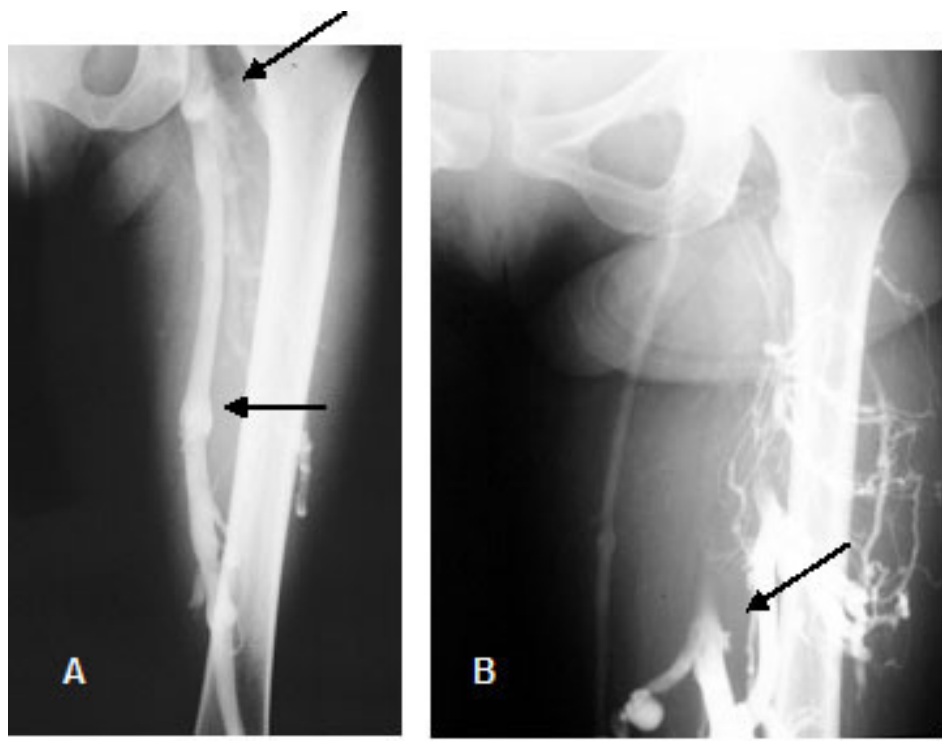

Figura 8: Flebografia.

A) Normal: nota-se veia femoral com válvulas (setas);

B) Trombo obstruindo totalmente a veia femoral (seta). 
tanto, o emprego de fibrinogênio humano marcado tem sido abandonado, em virtude de potenciais doenças transmitidas (hepatite, HIV, etc.).Nos pontos previamente marcados, o aumento de radioatividade corresponde a depósito de fibrina, ou seja, o trombo (Figura 9-B).

\section{4- TROMBOFLEBITE SU- PERFICIAL}

As tromboflebites superficiais podem ser distinguidas em espontâneas e as desencadeadas por uso de cateter ou injeção de drogas diretamente nas veias superficiais.

As espontâneas surgem em indivíduos que apresentam estados de hipercoagulabilidade (trombofilias hereditárias e adquiridas). Na maioria das vezes está associada a alterações secundárias de coagulação e/ ou ou fibrinólise: neoplasia, gravidez, uso de ACO, outras condições que propiciam estase venosa como varizes de membros inferiores, imobilização e ainda condições de disfunção endotelial como doença de Behcet, Mondor e Buerger.

A reação inflamatória da parede venosa e das adjacências costumam ser geralmente intensas. A embolia pulmonar é relativamente pouco freqüente, mas pode ocorrer se o trombo se estender proximalmente, atingindo o sistema profundo.

O quadro clínico é de início geralmente agudo, persistindo durante 1 a 3 semanas. Os sintomas e sinais costumam ser locais. Há processo inflamatório: calor,dor, rubor (eritema) caracterizado à palpação por

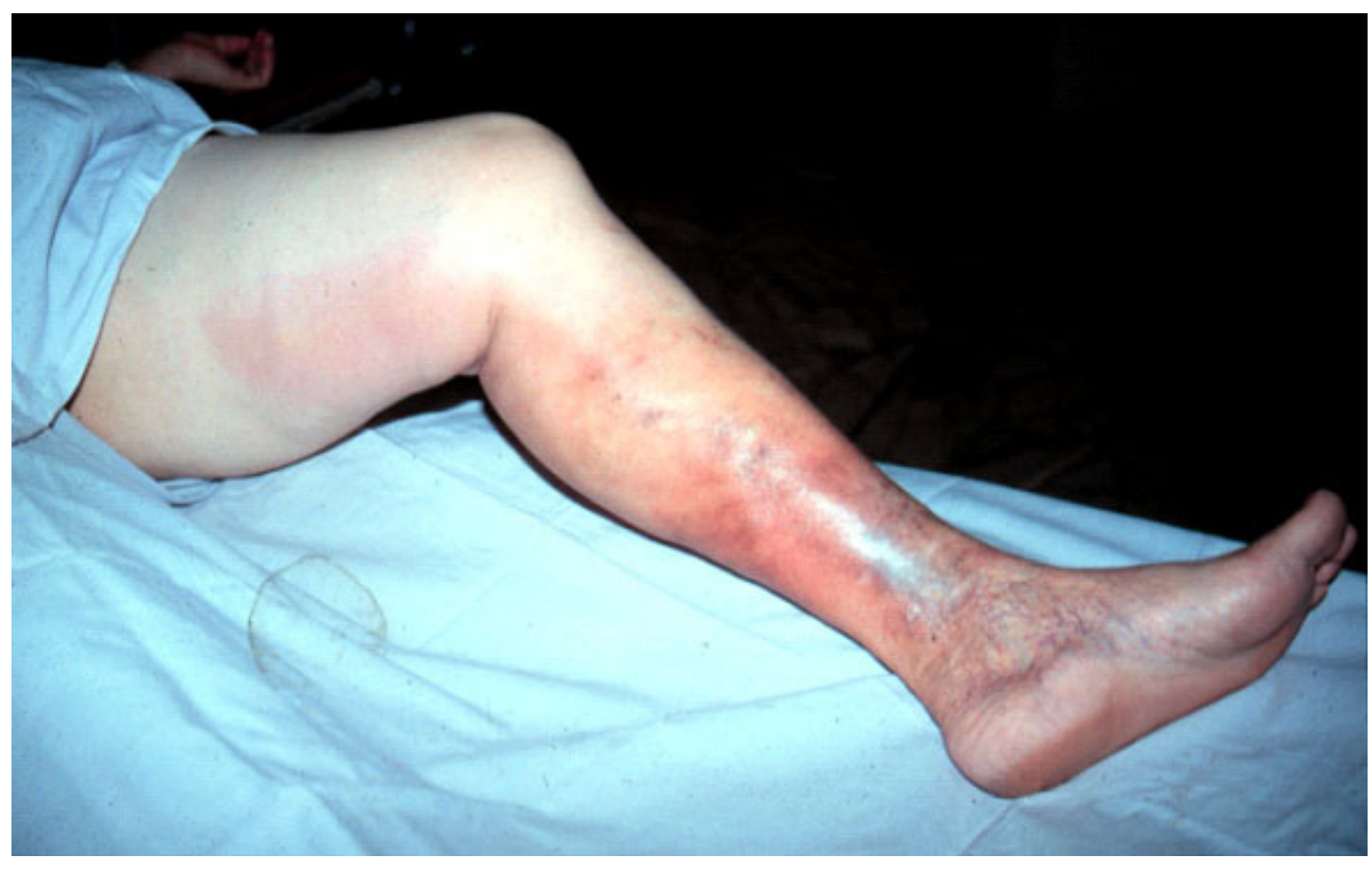

Figura 10. Tromboflebite superficial de safena magna 
cordão endurecido doloroso e aumento da temperatura ao longo do trajeto venoso (Figura 10).
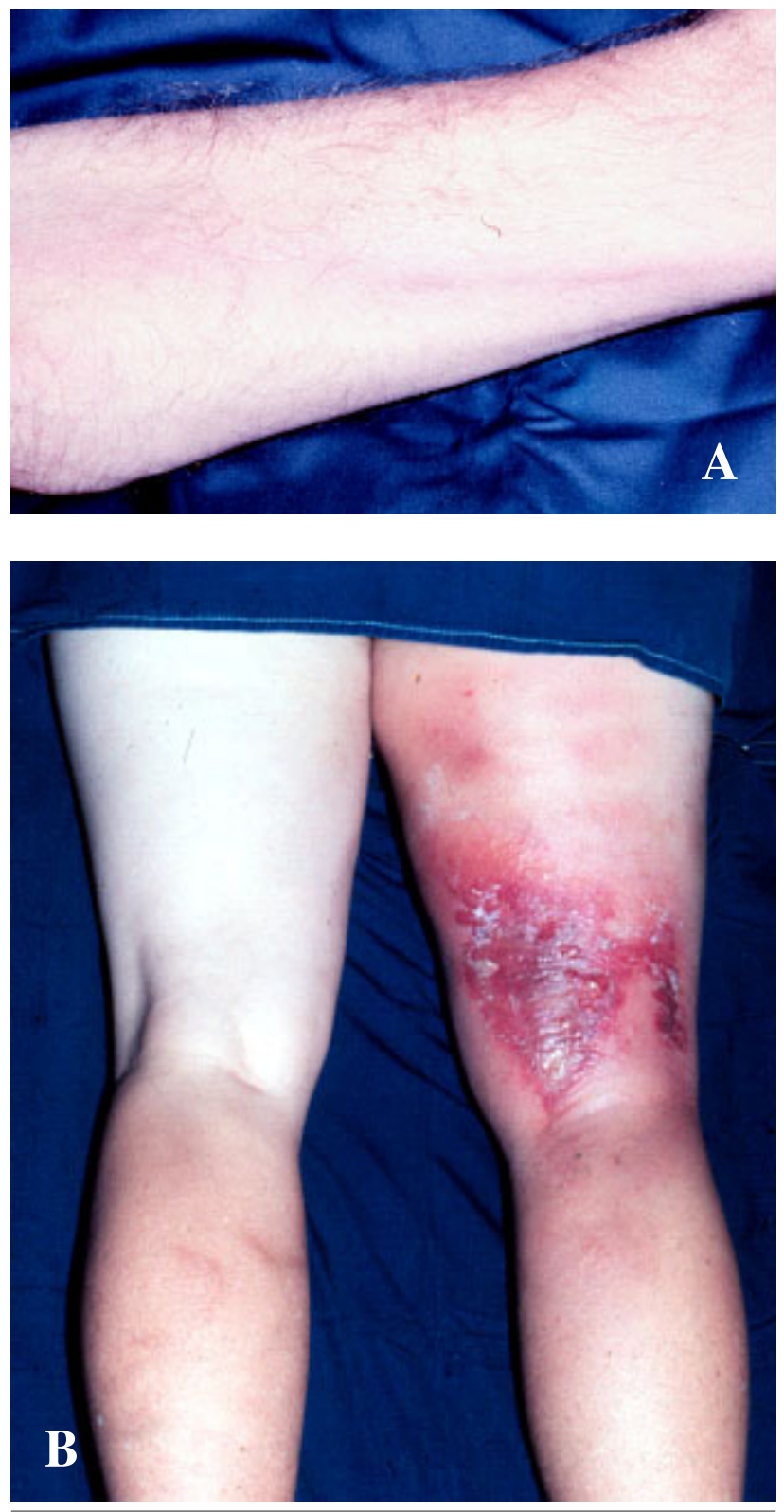

Figura 11: A) Linfangite; B) Erisipela

O diagnóstico diferencial deve ser feito com linfangite (Figura 11A), erisipela (Figura11 B) e eritema nodoso.

O tratamento faz-se a base de anti-inflamatórios não hormonais via oral (aspirina $500 \mathrm{mg}$ duas vezes ao dia, ou outro anti-inflamatório) quando a dor é importante. Pomadas locais com ação analgésica também são prescritas (pomadas heparinóides). Por se tratar de processo inflamatório asséptico é contra-indicado o uso de antibióticos.
Quando a tromboflebite atinge a croça da safena magna há o risco eventual de TVP e de embolia pulmonar; neste caso, indica-se a ligadura da croça, o que pode ser feito sob anestesia local.

A tromboflebite superficial por cateterismo venoso é uma complicação muito comum no meio hospitalar pela utilização freqüente desta via para administração de líquidos e drogas em pacientes internados, particularmente em pacientes operados, em centros de terapia intensiva, centros de quimioterapia, etc.

As causas da tromboflebite são devidas à agressão da parede venosa pelo traumatismo do cateter ou punção, a presença do cateter, a natureza e a concentração das soluções injetadas e a infecção potencial local que é aumentada se o cateterismo se faz a céu aberto (daí a preferência pela punção percutânea).

A duração da infusão parece ser fator importante na gênese da tromboflebite, porisso os pacientes que necessitam manter maior tempo de utilização de veia cateterizada deve-se alterná-la a cada 4 ou 5 dias. Este último fato também justifica a punção percutânea ao invés do cateterismo venoso a céu aberto, pois uma vez a veia dissecada esta não poderá ser mais utilizada e o capital venoso do paciente vai se restringindo.

A manifestação clínica da tromboflebite superficial por cateterismo venoso caracteriza-se pela dor no local e o processo inflamatório na veia cateterizada $\mathrm{e}$, às vezes, febre, em geral mais alta que a da tromboflebite superficial espontânea.

O tratamento desta tromboflebite inclui a pronta remoção do cateter endovenoso (enviando-o ao laboratório para cultura e antibiograma, se houver crescimento bacteriano). Além disso, prescreve-se antibiótico, se possível, com base no antibiograma. Hemoculturas podem ser úteis nos casos de septicemias desencadeadas por tromboflebites sépticas.

\section{5- PROFIlAXIA DA TROMBOSE PÓS-OPE- RATÓRIA}

A profilaxia primária da TVP e da embolia pulmonar (EP) baseia-se em métodos físicos e/ou farmacológicos com o objetivo de impedir, ou pelo menos, diminuir a chance de um paciente desenvolver TVP ou EP em situação de risco.

Em virtude destes riscos serem altos, em alguns pacientes operados e ainda pelo caráter clinicamente silencioso da TVP, em pelo menos metade dos casos, a prevenção desta complicação pós-operatória atualmente se impõe. 
O método profilático ideal é o que oferecesse simplicidade, segurança e eficácia, aplicável a todos os pacientes com risco de TVP, que cobre todo o período de risco e seja economicamente viável.

\section{1- Os métodos mecânicos baseiam-se em:}

- Deambulação precoce: solicita-se ao paciente operado ou no pós-parto ou com doença clínica que se movimente ativamente (caminhar). Apesar dessa recomendação não se tem comprovação científica de sua eficiência.

- Elevação dos membros inferiores: quando possível é solicitada.

- Exercícios ativos e passivos das pernas: movimentação ativa (dorso-flexão, extensão e flexão dos membros) no leito ou mesmo passiva (quando acompanhantes dos pacientes colaboram com a movimentação do paciente). Apesar de empregado, este método também não tem eficácia comprovada.

- Compressão elástica (meia elástica): muito utilizada nos USA e na Europa, tem demonstrado eficácia em alguns trabalhos clínicos em diminuir a incidência de TVP em pacientes submetidos à cirurgia geral e à neurocirurgia. Pode ser associada a métodos farmacológicos.

- Estimulação elétrica de músculos da panturrilha: é de aplicação complicada e pouco utilizada.

- Compressão pneumática externa intermitente: realizada por botas (Figura 12) ou por perneiras infladas cíclica e sequiencialmente com ar, tem-se mostrado de valor na profilaxia da TVP em vários tipos de pacientes. É o método de escolha no caso em que os métodos farmacológicos aumentam o risco hemorrágico (pacientes politraumatizados ou neurocirúrgicos), etc.

\section{2- Métodos farmacológicos}

Os métodos farmacológicos são atualmente os mais empregados e estudados, por serem mais práticos. Podem ser associados aos métodos mecânicos. As drogas mais utilizadas neste método são:

- Heparina padrão em baixas doses: Utilizando-se mínimas doses de heparina padrão, comprovou-se a queda de incidência de TVP em cirurgia geral, de 22,4\% (controle) para 9,9\% nos pacientes tratados ${ }^{5}$.

- Heparina de baixo peso molecular (HBPM): Atualmente tem sido cada vez mais empregada em muitos países. As HBPM são preparadas a partir da heparina padrão, mediante processos químicos ou enzimáticos que fracionam a heparina em moléculas de 2000 a 6000 dáltons. Devido ao tamanho de suas moléculas, embora ajam como a heparina não fracionada, acelerando a ação da antitrombina, elas têm menor ação inibitória do fator IIa (trombina), atuando principalmente sobre o fator Xa, além de ter maior biodisponibilidade e vida média mais prolongada.

Em cirurgia geral, os efeitos da HBPM revelam que nos pacientes controles (sem a medicação) o índice de TVP é de $25 \%$, enquanto nos pacientes tratados o índice é de $7 \%$.

Não há necessidade de controle laboratorial no uso profilático das heparinas (provas de coagulação). Os principais efeitos colaterais da heparina (hemorragia, trombocitopenia e osteoporose) são maiores que aquelas das heparinas de baixo peso molecular. Doses e nome comercial das heparinas em uso atualmente estão na Tabela II.

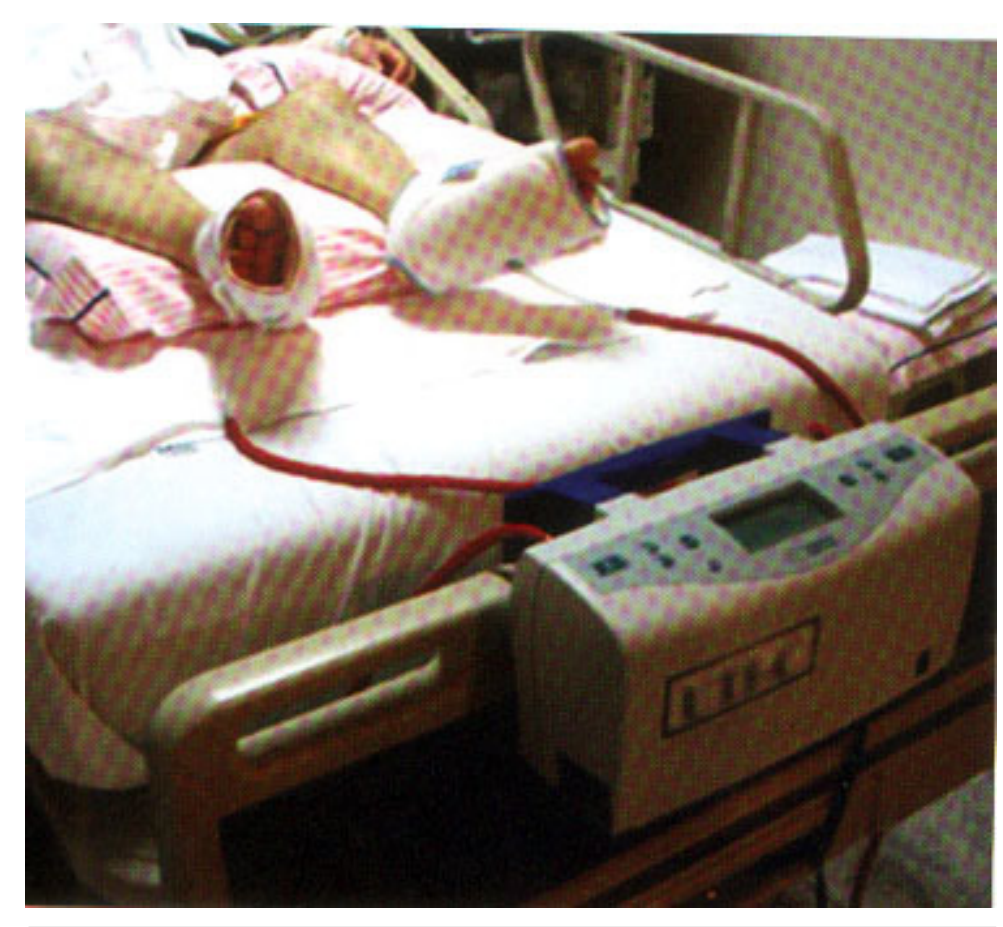

Figura 12: Equipamento de compressão pneumática intermitente. 
Tabela II: Doses profiláticas da heparina padrão e as heparinas de baixo peso molecular (HBPM).

\begin{tabular}{lccc}
\hline Drogas & Nome comercial & Doses & Início (antes operação) \\
\hline Heparina padrão & Liquemine & $5000 \mathrm{UI}$ & $2-4 \mathrm{~h}$ \\
Nadroparina & Fraxiparina & $12 / 12 \mathrm{~h} \mathrm{ou} 8 / \mathrm{h} \mathrm{h}$ & \\
& & $0,3 \mathrm{ou} 0,6 \mathrm{ml}$ & $2-4 \mathrm{~h}$ \\
Enoxaparine & $12 / 12 \mathrm{~h}$ \\
Clexane & $20 \mathrm{mg}-40 \mathrm{mg}$ & $2-4 \mathrm{~h}$ \\
Dalteparina & Fragmin & $24 \mathrm{~h}$ & $2-4 \mathrm{~h}$ \\
& & $2500 \mathrm{UI}$ & \\
\hline
\end{tabular}

- Anticoagulante oral: Apesar de terem sido utilizado no passado, o anticoagulante oral tem caído em desuso, por apresentar potencialmente maior risco de hemorragia.

- Dextran: O dextran tem ação preponderante sobre a viscosidade sanguiínea e sobre a adesividade plaquetária. Também já foi utilizado mas os resultados são contraditórios.

- Aspirina (ácido acetil salicílico): Tem ação antiplaquetária, mas não tem demonstrado qualquer efeito profilático da TVP.

Os riscos de desenvolver TVP no pós-operatório (modificado de Bergqvist, 2007) podem ser resumidos da seguinte forma:

- Baixo risco: Pacientes $>40$ anos com nenhum fator de risco. Pacientes $>40$ anos, cirurgias pequenas (30 min.) (TVP proximal < 1\%; embolia pulmonar fatal $0,01 \%)$.

- Risco moderado: Cirurgia maior: abdominal ou pélvica em pacientes com 40-60 anos, sem fatores de risco. Cirurgia em pacientes com menos de 40 anos, com mais de um fator de risco (TVP proximal 2 a 4\%; embolia pulmonar fatal 0,1 a $0,4 \%$ ) .
- Alto risco: Cirurgia em pacientes com 40-60 anos, com fator de risco adicional; Cirurgia em pacientes acima de 40 anos, com TVP ou EP prévia, neoplasia maligna ou grande operação ortopédica (TVP proximal - 4 a $8 \%$; embolia pulmonar fatal 0,4 a $1 \%)$.

Os métodos recomendados, na profilaxia da TVP, de maneira geral, são os seguintes:

- Cirurgias de baixo risco: métodos mecânicos (deambulação precoce, movimentação no leito).

- Cirurgias de risco moderado: métodos mecânicos (deambulação precoce) associados a métodos farmacológicos (Heparina 5.000 UI - 2h antes da operação e a seguir 12/12 h) ou Enoxaparina - 20 $\mathrm{mg}$ - $2 \mathrm{~h}$ antes da operação e a seguir $20 \mathrm{mg} /$ dia ou Nadroparina - 0,3 $\mathrm{ml}-2 \mathrm{~h}$ antes da operação e a seguir 0,3 ml - 12/12 h.

- Cirurgias de alto risco: métodos mecânicos (deambulação, movimentação) associados a métodos farmacológicos (Heparina - 5.000 UI 2 h antes da operação e a seguir 5.000 UI 8/8h ou Enoxaparina - $40 \mathrm{mg}-2 \mathrm{~h}$ antes e $40 \mathrm{mg} /$ dia ou Nadroparina 0,6 - $2 \mathrm{~h}$ antes e $0,6 \mathrm{ml} \mathrm{de} 12 / 12 \mathrm{~h}$ ).

Piccinato CE. Post-operative venous thrombosis. Medicina (Ribeirão Preto) 2008; 41 (4): 477-86.

ABSTRACT: The thromboembolic phenomena deep venous thrombosis and superficial venous thrombosis are caused by formation of a thrombus in the respective venous system. Here, the etiopathogenesis, the potential clinical as well as laboratory diagnostics and the possible prophylaxis in order to avoid these thromboembolic events are discussed.

keywords: Venous Thrombosis. Postoperative Period. 


\section{BIBLIOGRAFIA RECOMENDADA}

1 - Ferreira Filho AV, Alves SCF, Penosa Jr DC, Llorach-Velludo MAS, Cherri J, Piccinato CE. Incidência de embolia pulmonar em 3012 autópsias. 29․ . Congresso Brasileiro da Sociedade Brasileira de Angiologia e Cirurgia Vascular, Vitória (ES), 1991.

2 - Boccalon H. Explorations vasculaires. Techniques et applications. Paris : Masson, 1990.

3 - Maffei FHNA, Rollo HA. Trombose venosa profunda dos membros inferiores: incidência, patologia, patogenia, fisiopatologia e diagnóstico. In: Doenças vascualres periféricas. Maffei FHA, Lastória S, Yoshida WB, Rollo HÁ. 3ª . ed., Medsi, Rio de Janeiro, 2002, p. 1363-86.
4 - Nicolaides AN. Thromboembolism. Etiology, Advances in prevention and management. 1st Ed. University Park Press, Baltimore, 1975.

5 - Collins $R$ et al. Reduction in fatal pulmonary embolism and $v$ enous thrombosis by perioperative adminsitration of subcutaneous heparin. N Engl J Med 1988; 318 (1): 1672-73.

6 - Bergqvist D. Update on in hospital venous thromboembolism prophylaxis. Eur J Vasc Endosc Surg, 2007; 33: 343-50.

Recebido para publicação em 20/08/2008

Aprovado para publicação em 23/10/2008 